\title{
Uric acid promotes an acute inflammatory response to sterile cell death in mice
}

\author{
Hajime Kono, ${ }^{1}$ Chun-Jen Chen, ${ }^{2}$ Fernando Ontiveros, ${ }^{1}$ and Kenneth L. Rock ${ }^{1}$ \\ 1Department of Pathology, University of Massachusetts Medical School, Worcester, Massachusetts, USA. \\ 2Department of Biochemical Science and Technology, National Taiwan University, Taipei, Taiwan.
}

\begin{abstract}
Necrosis stimulates inflammation, and this response is medically relevant because it contributes to the pathogenesis of a number of diseases. It is thought that necrosis stimulates inflammation because dying cells release proinflammatory molecules that are recognized by the immune system. However, relatively little is known about the molecular identity of these molecules and their contribution to responses in vivo. Here, we investigated the role of uric acid in the inflammatory response to necrotic cells in mice. We found that dead cells not only released intracellular stores of uric acid but also produced it in large amounts postmortem as nucleic acids were degraded. Using newly developed $\mathrm{Tg}$ mice that have reduced levels of uric acid either intracellularly and/or extracellularly, we found that uric acid depletion substantially reduces the cell death-induced inflammatory response. Similar results were obtained with pharmacological treatments that reduced uric acid levels either by blocking its synthesis or hydrolyzing it in the extracellular fluids. Importantly, uric acid depletion selectively inhibited the inflammatory response to dying cells but not to microbial molecules or sterile irritant particles. Collectively, our data identify uric acid as a proinflammatory molecule released from dying cells that contributes significantly to the cell death-induced inflammatory responses in vivo.
\end{abstract}

\section{Introduction}

When cells undergo necrosis in vivo, they trigger an acute inflammatory response (1). Local blood flow is increased, venules leak protein-rich fluid, and leukocytes extravasate from the blood into the tissue. Neutrophils are the first cells recruited into the site of cell death, and this is followed later by an influx of monocytes. These events occur wherever significant necrosis occurs and are so reproducible that the progression of the inflammatory response is used forensically to date the time of tissue injury (2).

Why should cell death stimulate an inflammatory response? Necrosis is not typically a normal physiological event but rather occurs as a consequence of some pathological process that damages cells; as such, necrosis is a harbinger of a potential threat to the host (3). Presumably because of this, the innate immune system is rapidly mobilized to deliver the soluble and cellular defenses to a site of injury. Once deployed, the defenses will engage and attempt to neutralize or wall off any injurious agents that are present. They also help to clear dead cells and debris and stimulate mechanisms to repair tissue damage. On the other hand, recruiting the innate defenses comes at a price (4-6). The delivery of the immune effector mechanisms is imprecise, and as a result, normal healthy cells may be caught in the line of fire and damaged. Hydrolytic enzymes and highly reactive chemical compounds, such as oxygen radicals, leak from living and dying leukocytes, and these molecules inflict damage on cells in the environment. In infections, this process is often short lived and the resulting collateral damage is a small price to pay to contain a potentially life-threatening condition. However, in situations of sterile cell death, and when this process is chronic, the cost-benefit ratio is less favorable and can lead to disease. Because of these positive and negative effects, it is important to understand the mechanisms by which cell death leads to inflammation $(7,8)$.

Conflict of interest: This research is partially funded from sanofi-aventis (to $\mathrm{H}$. Kono).

Citation for this article: J Clin Invest. 2010;120(6):1939-1949. doi:10.1172/JCI40124
How does cell death actually provoke an inflammatory response? It is thought that cells contain immune stimulatory molecules (often referred to as damage-associated molecular patterns [DAMPs]) that are not exposed in living cells, but are released upon necrosis (9-11). The innate immune system has evolved the capacity to recognize and then respond to the presence of DAMPs. There may be different classes of DAMPs that act on different cellular targets and have different biological effects. For example, some DAMPs may trigger inflammation (referred to herein as proinflammatory DAMPs) (12) and others may function as adjuvants to promote adaptive immune responses (13), while yet others may affect other processes such as tumor behavior (14).

The molecular identity of the proinflammatory DAMPs is very poorly understood. A few potential candidate molecules have been recently described, including molecules such as HMGB1 (12), SAP130 (15), myosin heavy chain (16), and fragments of extracellular matrix components (generated from hydrolases released from dead cells) $(17,18)$. However while these molecules have proinflammatory potential, their actual role in cell deathinduced inflammation in vivo is for the most part unclear. For example, while HMGB1 can induce inflammation (12), necrotic mutant cells lacking HMGB1 are as proinflammatory as WT cells (19); whether this is because HMGB1 is not truly a proinflammatory DAMP in vivo or redundancy in proinflammatory DAMPs makes its presence nonessential is not clear. Determining the molecular identity of DAMPs and their contribution to inflammation in vivo is important because these molecules could be targets for therapeutic intervention to prevent or treat diseases caused by cell death-induced inflammation.

We had previously found that uric acid is released from dying cells, where it then functions as an adjuvant that promotes the generation of adaptive immune response $(13,20)$. It is thought that the active form of this molecule is monosodium urate, which acts to promote immune responses by stimulating dendritic cells. Independent of this and in other settings, monosodium urate crys- 
tals can trigger inflammation, and when this occurs spontaneously in hyperuricemic patients, it causes the inflammatory disease of gout (21). These findings have led us to hypothesize that uric acid released from dying cells might function as a proinflammatory DAMP that contributes to cell death-induced inflammation. The studies in this report were designed to test this hypothesis.

\section{Results}

Uricase Tg mouse models. To analyze the roles of uric acid in vivo, it would be useful to have animals that are deficient in this molecule. It is possible to lower the levels of uric acid in animals using pharmacological approaches. One approach has been to block its synthesis. Uric acid is generated from xanthine by xanthine oxidase, and this reaction can be inhibited by the uric acid analogue allopurinol (22). A limitation of this approach is that it only partially reduces but does not eliminate uric acid from cells and body fluids. Another approach is to deplete uric acid by administering uricase, an enzyme, which oxidizes uric acid into allantoin and water. This treatment can markedly lower uric acid levels but has limitations in its pharmacokinetics, including slow distribution into interstitial fluids and rapid clearance from the blood; also, currently available sources of this enzyme are immunogenic in mice and elicit neutralizing antibodies, precluding long term use in vivo (23). Because of these issues, it would be attractive to have genetic models that are stably deficient in uric acid that could be used in addition to the pharmacological treatments. Unfortunately, mice that are genetically deficient in xanthine oxidase, and therefore unable to produce uric acid, are runted at birth and die after several weeks (24).

We decided to pursue a different approach to develop uric aciddeficient mice. We hypothesized that the expression of murine uricase as a transgene might be able to chronically reduce uric acid levels in tissues and overcome some of the limitations of the other available approaches. Uricase is only expressed in the liver of mice. We cloned this gene from mouse liver and used it to produce 2 different constructs. In one construct, the uricase cDNA was fused with a signal sequence from the adenovirus E3-gp19K gene so that when expressed, the uricase protein would be secreted into the extracellular fluids (Figure 1A and ref. 25). The idea here was that the secreted uricase would deplete uric acid from the interstitial fluids of tissues. In another construct, the uricase cDNA was targeted to peroxisomes using its endogenous targeting sequence (Figure 1A; this is referred to herein as the intracellular uricase construct). The idea behind this construct was that the transgene should reduce intracellular pools of uric acid and, after cells die and release the enzyme, also deplete uric acid from the environment of dead cells. Thus these $2 \mathrm{Tg}$ animals were designed to lower uric acid levels around dying cells but to do so in different ways. Both the secreted and intracellular uricase constructs were placed under the control of the $\beta$ actin promoter so that they would be expressed and exert their effects broadly in most tissues (26). These uricase constructs were injected into the nuclei of fertilized C57BL/6 eggs, and several independent $\mathrm{Tg}$ founders were generated. The animals were viable, fertile, and without any obvious phenotypic abnormalities. A third construct was also generated wherein the peroxisomal targeting sequence was deleted so that the uricase would be expressed in the cytosol; however, cells did not tolerate stable expression of this cDNA, so it was not used in our studies (data not shown).

We analyzed the expression of uricase by Western blot in serum and tissue lysates from WT and Tg animals. Uricase was undetectable in the serum of WT mice and those Tg for the intracellular construct, as expected (Figure 1B). In contrast, uricase was present in the serum of mice $\mathrm{Tg}$ for the signal sequence-uricase construct, indicating that the transgene was secreted, as expected (Figure 1B). Presumably most of the enzyme in the serum originates from the interstitial fluids (delivered after drainage through lymphatics) and possibly also from cells in the blood and tissues with sinusoidal architecture (e.g., the spleen, liver, and bone marrow). In WT animals, uricase was undetectable in all tissues except for the liver, as expected (Figure 1B). In contrast, uricase was detectable in all tissues of both $\mathrm{Tg}$ animals, including in the liver, where it was present in elevated amounts compared with WT mice (Figure 1B). Therefore, the Tg uricase constructs were expressed with the expected distribution.

To verify that the Tg uricase was active, we also performed enzyme assays on serum and tissue lysates. Uricase activity was only detected in the serum of the secreted uricase Tgs and not the intracellular ones or WT animals. The lysates from all organs examined from both Tgs contained active uricase (Figure 1C), while all tissues from WT mice except liver lacked this activity. The content of the secreted uricase varied between different tissue lysates, presumably due to differences in the amount of this enzyme in the ER, exocytic pathway, and possibly extracellular fluid. Interestingly, lysates of most tissues from animals injected i.v. 18 hours earlier with recombinant uricase had little or no uricase activity, presumably because the enzyme remained intravascular and/or was cleared; the exception was the lung (Figure 1C). These results indicate that recombinant intracellular and secreted forms of uricase are enzymatically active, both in cells and, when secreted, in the extracellular environment and serum of mice.

Uric acid levels in uricase Tg mice. We next examined the effects of the expressed uricase on uric acid levels in the various $\mathrm{Tg}$ mice. In the mice expressing secreted uricase, we predicted that there would be a reduction in uric acid levels in the interstitial fluids. We evaluated this prediction in the resident peritoneal fluid sampled by lavage. As predicted, uric acid levels in peritoneal fluid of the secreted uricase $\mathrm{Tg}$ mice were significantly reduced compared with WT animals, although the reduction was not complete $(\sim 60 \%$; Figure 1D). We also measured uric acid levels in freshly isolated serum and found that they were reduced by approximately $30 \%$ in the secreted uricase $\mathrm{Tg}$ animals; although this reduction was more modest than in the peritoneum, it was significant $(P<0.05$; Figure $1 \mathrm{E})$. The greater reduction in uric acid in the tissue fluids compared with the serum is likely to reflect the direct secretion of uricase into the tissue fluids, where because of the small volume of fluid, the enzyme is presumably at higher concentration than after it is resorbed and distributed throughout the serum. To determine whether the secreted uricase was sufficient to inhibit inflammatory responses to uric acid, we injected monosodium urate crystal i.p into control or ssUOX Tg mice and found that the resulting inflammatory responses were significantly inhibited by the secreted uricase (Figure 1F).

Upon incubating the serum of WT animals, ex vivo uric acid levels were stable (Figure 2A). There was a slow and modest reduction in uric acid levels upon incubation of serum from the intracellular Tg mice, indicating the presence of a small amount of uricase (Figure 2A). In contrast after incubation of serum from the secreted uricase $\mathrm{Tg}$ mice, uric acid levels rapidly fell to undetectable levels, reflecting the activity of the uricase present in the serum (Figure 2A). The fact that uric acid was still present at all in the presence of active uricase in the serum indicates that in vivo, 
A

\begin{tabular}{ll|cr|} 
ssuOX & gp19K-ss & UOX & PTS \\
\cline { 2 - 4 } intuox & & UOX & PTS \\
\cline { 2 - 4 } & & &
\end{tabular}

B:
IB: uricase
IB: $\alpha$-tubulin
IB: uricase
IB: $\alpha$-tubulin
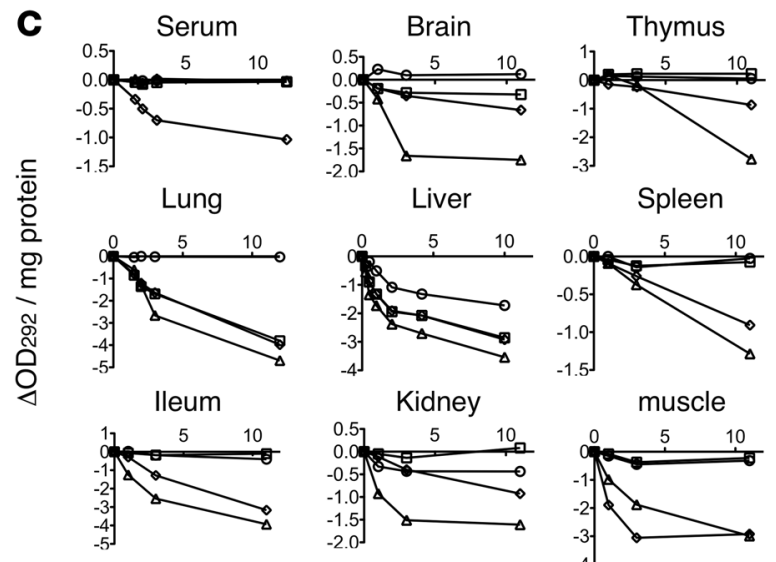

Spleen
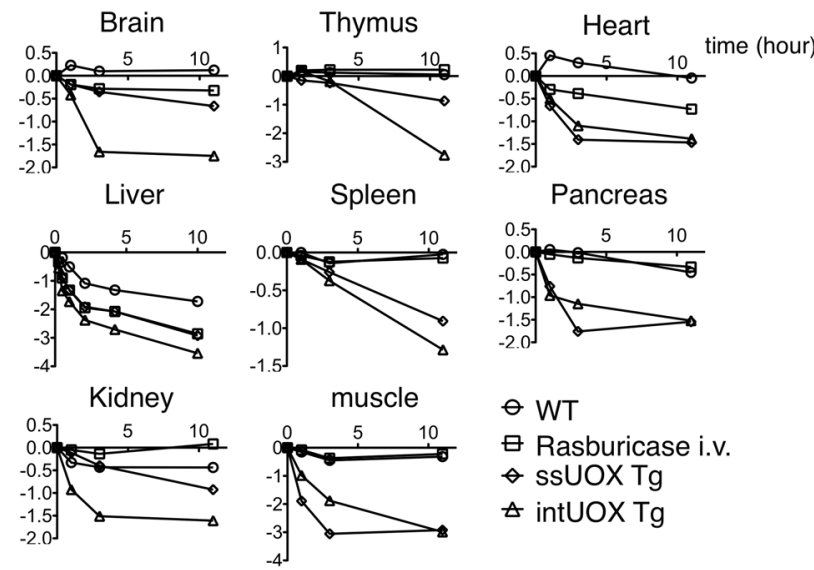

Pancreas

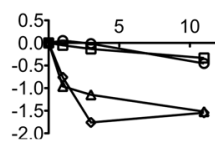

$\theta$ WT

$\boxminus$ Rasburicase i.v.

$\Leftrightarrow$ ssUOXTg

$\triangle$ intUOX Tg
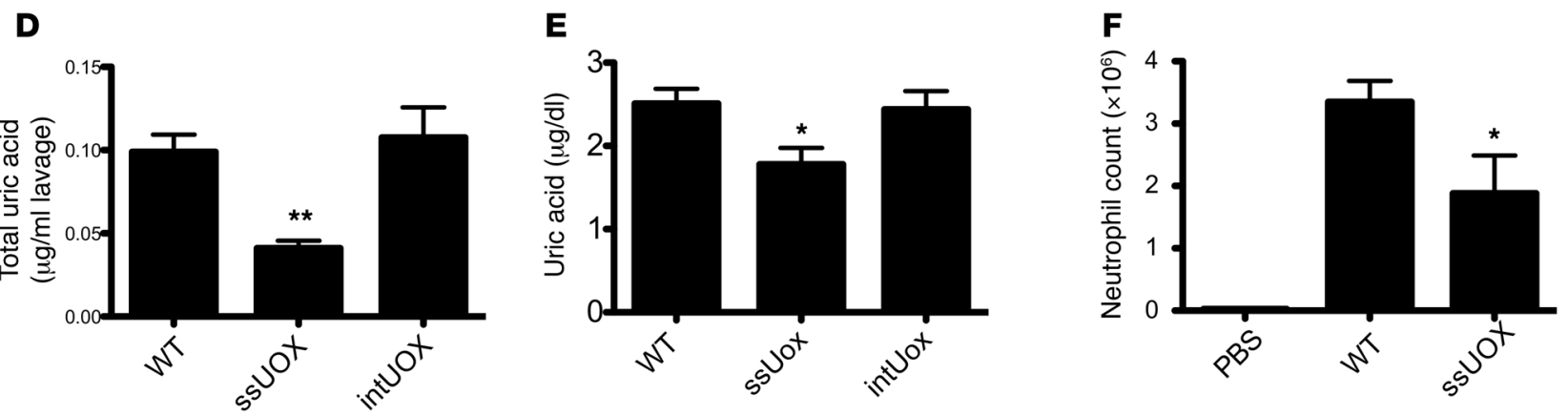

Figure 1

Generation and characterization of uricase Tg mice. (A) Construct of uricase transgenes. Secreted uricase (ssUOX) was generated by N-terminal addition of a signal sequence for secretion derived from adenovirus gp19K (gp19K-ss). The unmodified intracellular uricase (intUOX) has a C-terminal peroxisome targeting signal sequence (PTS). (B) Western blot of uricase and $\alpha$-tubulin (loading control) in organs of Tg or WT mice. (C) Uricase activity in organs and serum. WT C57BL/6 mice were injected with $9 \mu \mathrm{g}$ of i.p. and $9 \mu \mathrm{g}$ of i.v. rasburicase where indicated. Organs were harvested from untreated WT, uricase Tg mice, or WT mice 18 hours after rasburicase injection, and lysates were prepared. Twenty $\mu$ l of lysate form various organs was added to $1 \mathrm{ml}$ of uric acid solution $\left(\mathrm{OD}_{292}=1.0\right)$ and incubated at $37^{\circ} \mathrm{C}$ for indicated periods of time. The uricase activity was measured by the decrease of $\mathrm{OD}_{292 .}$ (D) Amount of uric acid in peritoneal cavity in WT and uricase Tg mice $(n=6)$. (E) Plasma concentration of uric acid in WT and uricase Tg mice. Samples were drawn and immediately chilled on ice to prevent uricase from oxidizing uric acid ex vivo $(n=13-19)$. (F) Total neutrophil numbers in the peritoneal cavity after 15 hours after i.p. injection of 2 mg of monosodium urate crystal. $n=6$ (PBS); $n=15$ (WT); $n=8$ (ssUOX). ${ }^{* *} P<0.01 ;{ }^{*} P<0.05$ versus WT in (D-F).

the production of uric acid exceeds its removal. Since uric acid levels are regulated in vivo by cellular production as well as adsorption from the gut and readsorption in the kidney (27), it is possible that in the $\mathrm{Tg}$ mice, there have been compensatory increases in these processes in response to the loss of uric acid; however, this issue has not been investigated. There was no increase in uric acid in homogenates of any tissue in ssUOX Tg mice, and rather some decrease was found in several organs. In any case, these data 

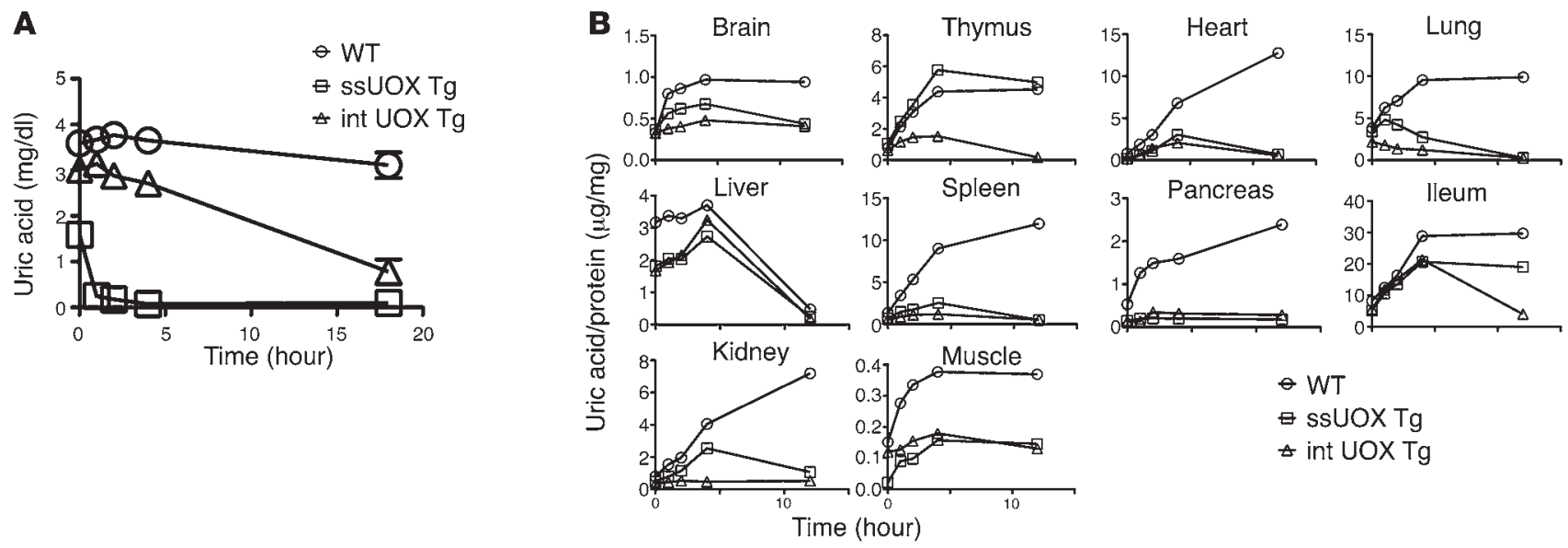

$\ominus W T$

$\because$ ssUOX Tg

$\star$ int UOX Tg
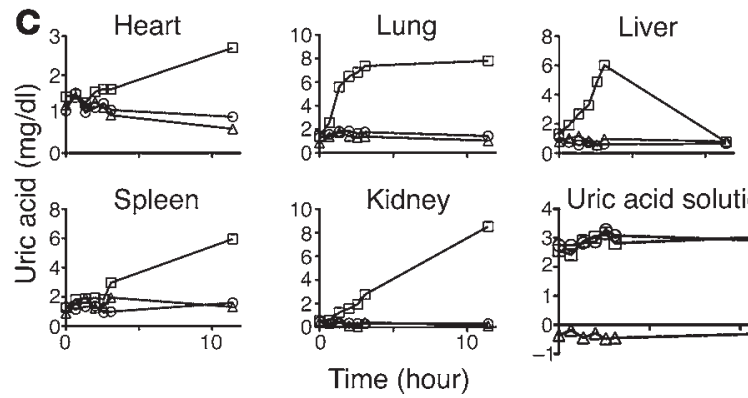

$\exists$ None Treat

$\theta$ Allopurinol

* Uricase

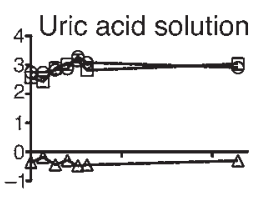

Figure 2

Generation of uric acid after cell death. (A) Change of uric acid concentration in serum of WT and uricase Tg mice incubated ex vivo. Serum from uricase Tg mice was collected after being allowed to clot at room temperature and subsequently incubated at $37^{\circ} \mathrm{C}$ for the indicated times; uric acid concentration was measured $(n=32-36)$. (B) Generation of uric acid after cell death. Tissue lysates obtained from the indicated organs from uricase $\mathrm{Tg}$ mice or WT littermates were incubated at $37^{\circ} \mathrm{C}$ for indicated times. Uric acid content was normalized with protein concentration. (C) Postmortem uric acid is generated by xanthine oxidase. Tissue lysates were incubated at $37^{\circ} \mathrm{C}$ for indicated times in the presence of allopurinol $(128 \mathrm{mg} / \mathrm{l})$ or uricase $(0.5 \mathrm{mg} / \mathrm{ml})$. The uric acid concentrations in the tissue lysate are shown.

indicate that the secreted uricase Tg mice have a significant reduction in uric acid levels in extracellular fluids and serum.

In mice $\mathrm{Tg}$ for the intracellular uricase construct, we examined the intracellular levels of uric acid. In the majority of Tg tissues, we found a partial but significant reduction $(30 \%-70 \%)$ in intracellular levels of uric acid compared with WT cells (Figure 2B and Supplemental Figure 1; supplemental material available online with this article; doi:10.1172/JCI40124DS1). Interestingly, when the dead cells were cultured at $37^{\circ} \mathrm{C}$, as would occur when cells die in vivo, we observed a marked increase in uric acid levels in WT cells. This increase in synthesis was blocked by inhibitors of xanthine oxidase, indicating that purines were being metabolized into uric acid postmortem (Figure 2C). Remarkably, this postmortem increase in uric acid was suppressed in both intracellular and secretable uricase $\mathrm{Tg}$ mice. These data indicate that the intracellular and secretable recombinant uricase is released from dead cells and eliminates the endogenous and newly produced uric acid in the local environment. Serum levels of uric acid were not reduced in the intracellular uricase Tgs (Figure 1E), and this was not surprising, given that a substantial amount of uric acid originates from the diet (absorbed from the gut) and that there was only a partial reduction in intracellular stores of uric acid in the Tgs. Moreover, there is little of the intracellular uricase released into the serum (Figure $1 \mathrm{~B}$ and Figure 2A).

In summary, the $2 \mathrm{Tg}$ animals have different distributions of uricase and correspondingly partial but significant reductions in uric acid in different body compartments. The secreted uricase $\mathrm{Tg}$ has uricase and reduced uric acid in the extracellular fluids. The intracellular uricase $\mathrm{Tg}$ animals have uricase intracellularly that reduces intracellular, but not extracellular, pools of uric acid. In addition, the $\mathrm{Tg}$ uricase is released in active form from dead cells and then eliminates uric acid in and around the dead cells. Thus these 2 different transgenes will reduce uric acid around dying cells but do so in somewhat different ways.

Effect of uric acid depletion on inflammation to cell death in the liver. To examine the role of uric acid in cell death-induced inflammation, we used a well-established liver injury model in which mice were treated with a toxic dose of acetaminophen (19). This drug is metabolized in the liver to N-acetyl-p-benzoquinone imine, which causes necrosis in the centrilobular regions of this organ. The resulting sterile cell death stimulates a robust neutrophilic inflammatory response, which can be quantified by measuring the content of a neutrophil-specific enzyme myeloperoxidase (MPO) in the liver (19). The extent of liver injury can be quantified by measuring the amount of liver cytosolic enzymes (alanine aminotransferase $[\mathrm{ALT}]$ ) released and present in the serum.

The 2 uricase Tg mouse models and WT mice were treated with a single toxic dose of acetaminophen. The resulting inflammatory response to cell death in the liver was quantified and found to be very different in the WT versus uricase Tg mice. The injured liver in WT animals developed robust neutrophilic inflammation, while the inflammation in the injured livers of $\mathrm{Tg}$ mice was markedly reduced (Figure $3 \mathrm{~A}$ ). The reduction in the inflammatory response 


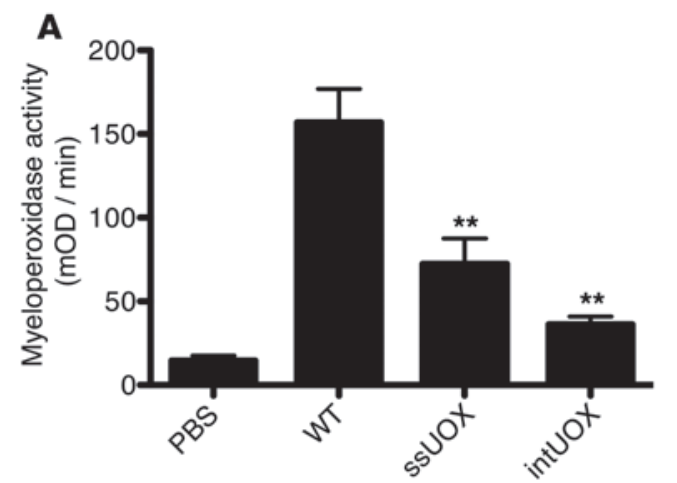

C

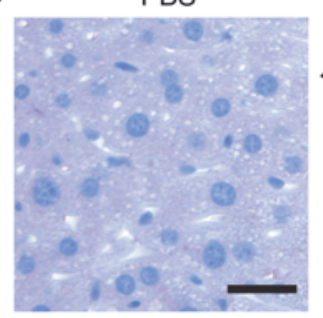

D

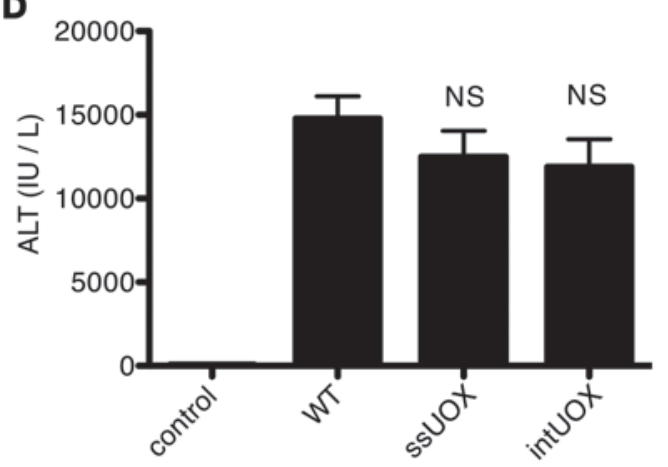

$F$

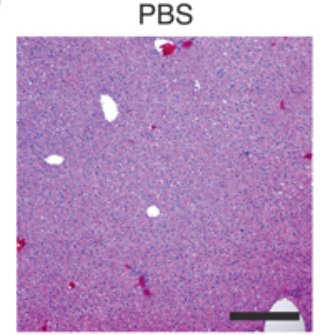

WT
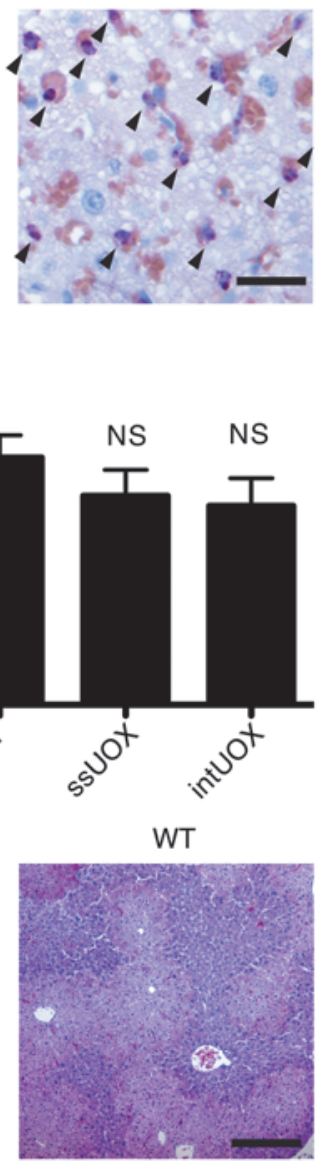

B
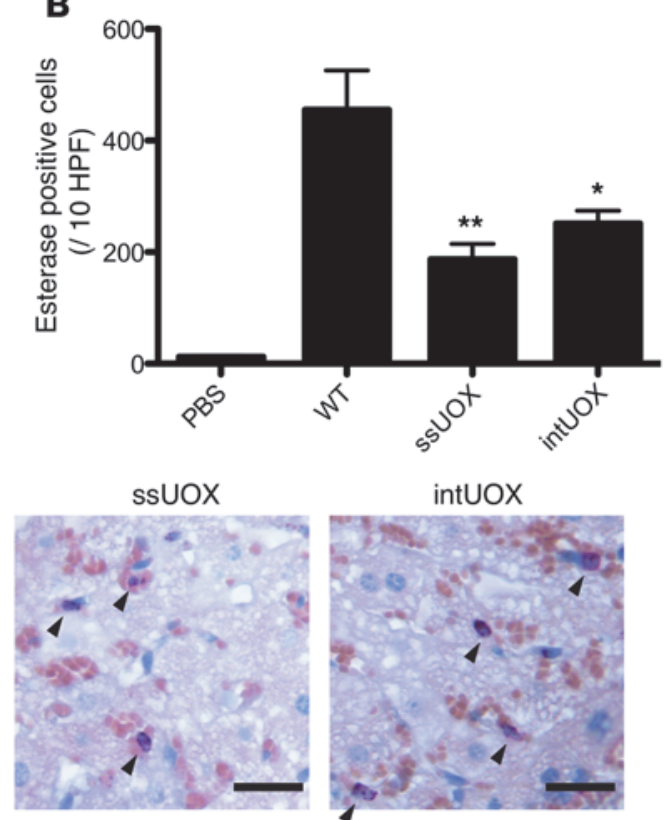

E

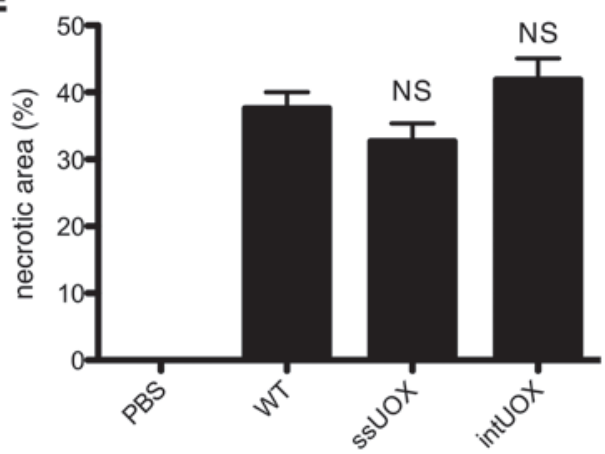

ssUOX
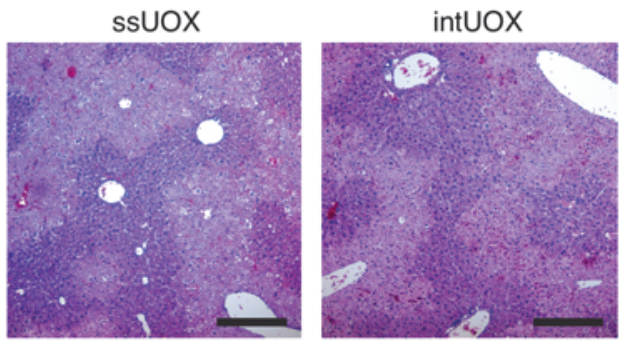

\section{Figure 3}

Reduced neutrophil recruitment to liver injury in uricase Tg mice. Liver tissue MPO activity (A), number of esterase-positive cells (neutrophils) (B), histology of sections stained for esterase activity (C), serum ALT activity (D), quantification of necrotic area (E), and histology of liver sections stained with H\&E (F) of WT and uricase Tg mice 18 hours after challenge with $300 \mathrm{mg} / \mathrm{kg}$ acetaminophen. Total numbers of mice used in $\mathbf{A}$ and D from 4 independent experiments were $n=6$ (PBS control); $n=26$ (WT); $n=24$ (ssUOX); and $n=23$ (intUOX). Total numbers of mice used in B and E were $n=6$ (PBS control); $n=8$ (WT); $n=5$ (ssUOX); and $n=5$ (intUOX). Means and SEM values are shown. ${ }^{* \star} P<0.01 ;{ }^{*} P<0.05$. NS, not significant versus control WT C57BL/6. (C) Representative images of esterase staining used in the analysis of B. Arrowheads indicate the esterase-positive cells. Scale bars: $25 \mathrm{~mm}$. (F) Representative images of H\&E staining used in the analysis of E. Scale bars: $250 \mathrm{~mm}$.

was seen both in the intracellular and secreted uricase Tg mice, with a somewhat larger inhibition with the intracellular construct (Figure 3A). The inflammatory cell infiltrate in the treated livers was further characterized by dissociating the liver into a singlecell separation followed by immunofluorescent staining and flow cytometry (Supplemental Figure 2). Eighteen hours after injury, the predominant inflammatory cells were neutrophils (as expected) and their numbers were significantly reduced in both uricase Tgs. There were many fewer monocytes, macrophages, T cells, or B cells at this time point after injury, and their numbers were not significantly reduced in either of the uricase Tgs (Supplemental Figure 2). Immunohistochemical detection of neutrophils by staining 

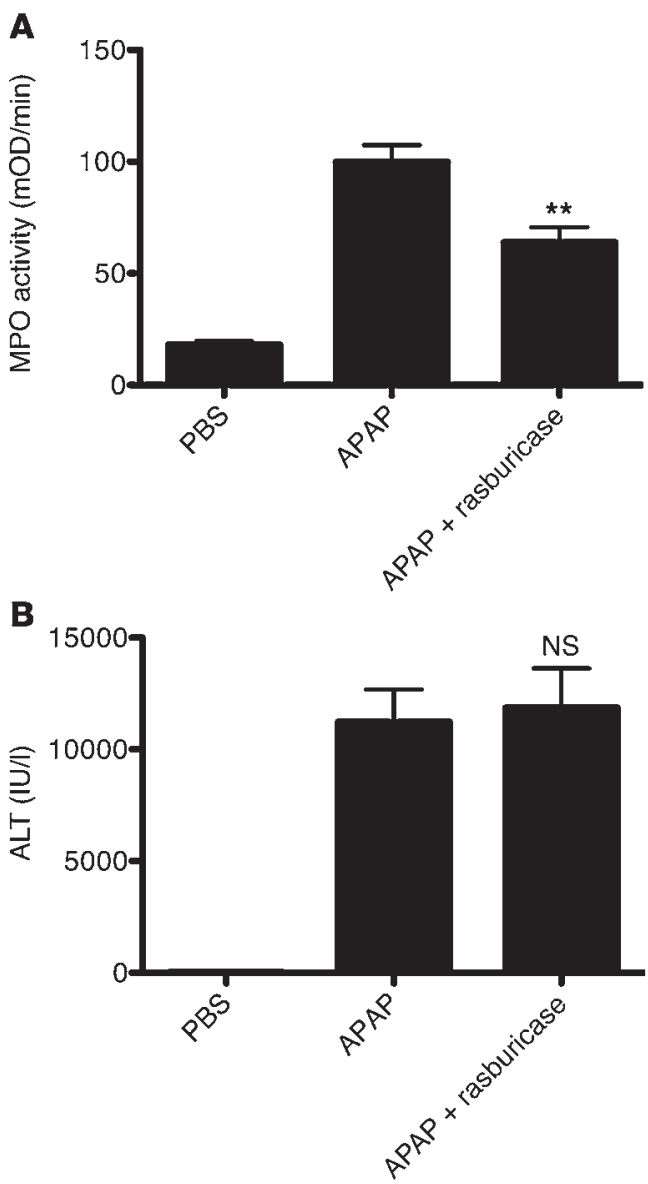

for esterase activity similarly revealed infiltrating neutrophils and a reduction in their numbers in both of the uricase Tg mice (Figure 3, $\mathrm{B}$ and $\mathrm{C})$. In addition to measuring MPO in the liver, we assayed the levels of proinflammatory cytokines in the control and treated animals. We could detect elevated levels of IL-1ßMIP2 and KC of treated control animals, and the levels of these proinflammatory mediators were significantly reduced in the serum and/or liver of the UOX-Tg mice (Supplemental Figure 3).

In contrast, ALT enzyme levels rose in the serum of both WT and $\mathrm{Tg}$ mice to levels that were not significantly different, indicating that the amount of drug-induced hepatocellular injury was similar and not affected by uricase expression (Figure 3D). This was further confirmed by histopathological examination of liver sections; both WT and both uricase Tg mice showed similar levels of centrilobular necrosis (Figure 3, E and F). At this early time point, there was no evidence of fibrosis or vascular damage, as expected. Therefore, the expression of uricase was inhibiting the inflammatory response to hepatocyte injury and doing so whether the transgene was secreted or intracellular. It should be noted we and others have previously reported that liver cell damage can be reduced by blocking inflammation $(19,28)$ and this protective effect was not seen in these experiments; this is presumably because inflammation needs to be inhibited almost completely to see this effect.

These results suggest that uric acid is released from (and based on the data in Figure 2B, potentially further generated by) dying hepatocytes and that the UOX reduces the levels of this molecule in the injured liver. To further investigate this issue, we measured

\section{Figure 4}

Reduced neutrophil recruitment to liver injury in mice treated with rasburicase. Liver tissue MPO activity (A) and serum ALT activity (B) of control and rasburicase-treated mice 18 hours after challenge with $300 \mathrm{mg} / \mathrm{kg}$ acetaminophen. $n=6$ (PBS); $n=20$ (APAP); $n=18$ (APAP + rasburicase). Means and SEM values are for combined data from 4 independent experiments. ${ }^{* *} P<0.01$, versus control APAP alone group. NS, not significant versus APAP alone.

the content of uric acid in the livers of controls and acetaminophentreated mice. Uric acid levels were significantly elevated in the injured liver of control mice, and these levels were reduced in both the ssUOX and intracellular UOX Tg mice (Supplemental Figure 4).

We also examined the effect in this model of reducing uric acid concentrations acutely through injection of recombinant uricase. This treatment also did not reduce the amount of liver injury caused by acetaminophen injection, as assessed by the release of ALT into the serum (Figure 4B). However, the recombinant uricase did reduce uric acid levels in the liver (Supplemental Figure 4) and cause a partial but significant reduction in liver inflammation after injury (Figure 4A). The degree of inhibition of inflammation was less than that seen in the uricase $\mathrm{Tg}$ animals, presumably because the injected uricase is less bioavailable at the site of injury. The fact that qualitatively similar results were obtained when uric acid levels were reduced by the expression of the transgenes or acute injection of uricase argues against the possibility that chronic uric acid depletion in the Tgs might somehow be leading to adaptations that indirectly affected the inflammatory response.

In another set of experiments, we investigated the effect on inflammation to tissue injury of reducing uric acid levels using allopurinol to block its synthesis. We confirmed that allopurinol treatment lowered intracellular concentrations of uric acid in the liver (Figure 5A) and found that it did not significantly reduce its levels in serum in this time period (not shown). Although this treatment similarly did not significantly reduce the amount of liver injury caused by acetaminophen injection, it did inhibit the ensuing inflammatory response (Figure 5, B and C). This result is important because it confirms the results obtained with $\mathrm{Tg}$ and injected uricase and does so by lowering uric acid though a completely different mechanism. This argues strongly that the reduced inflammation to cell death is due to uric acid depletion and not some other pleiotropic effect of the treatments.

Effect of uric acid depletion on inflammation to other necrotic cells in the peritoneal cavity. To determine whether uric acid was playing a role in death-induced inflammation to other cell types and in another anatomic location, we evaluated the effect of depleting uric acid on inflammatory responses to dead cells injected into the peritoneum. Injection of necrotic EL4 (a syngeneic T cell lymphoma) into the peritoneum elicits strong neutrophilic inflammation (Figure 6A), as previously reported $(19)$. The number of cells $\left(3 \times 10^{7}\right)$ injected was chosen to obtain robust responses and are relevant to in vivo situations where even much larger numbers of cells die under pathological conditions (e.g., myocardial infarct or toxic damage). This inflammatory response is partially but significantly reduced when uric acid is depleted by injection of recombinant uricase (Figure 6A). We similarly found that the inflammatory response to dead cells injected i.p. was reduced in the ssUOX Tg mice (Supplemental Figure 5).

Similar results were also obtained when dead cells from primary (noncultured) tissues were used instead of EL4. Intraperitoneal injection of necrotic lung homogenates elicited neutrophilic 
A

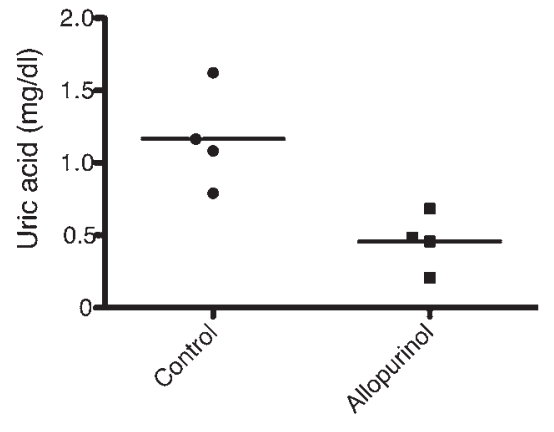

B

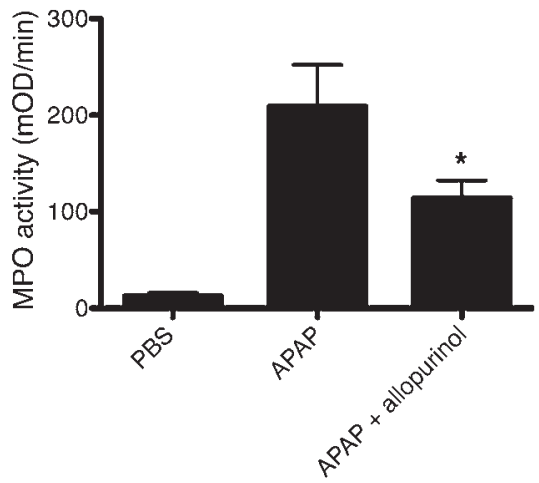

C

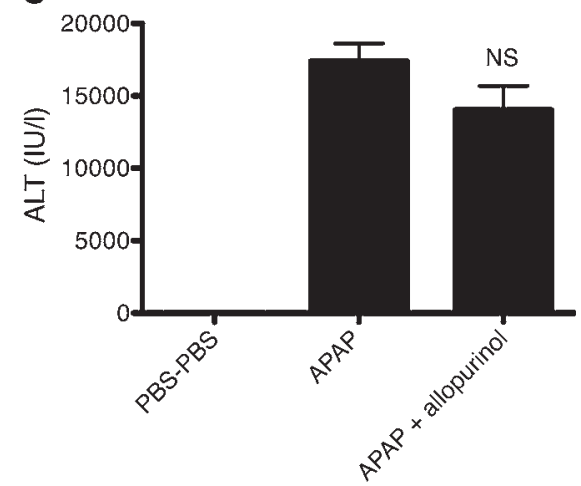

Figure 5

Reduced neutrophil recruitment to liver injury by allopurinol treatment. (A) Uric acid concentration in liver lysate treated with 1 week of i.p. injections of allopurinol (10 mg/kg/d). Liver tissue MPO activity (B) and serum ALT activity (C) of control and allopurinol-treated mice 18 hours after challenge with $300 \mathrm{mg} / \mathrm{kg}$ acetaminophen. $n=6$ (PBS); $n=17$ (APAP); $n=17$ (APAP + allopurinol). Means and SEM values are for combined data from 3 independent experiments. ${ }^{*} P<0.05$, versus control APAP alone group. NS, not significant versus APAP alone.

inflammatory responses, and injection of uricase reduced these responses significantly (Figure 6, C and D). Similarly, when necrotic lung from the intracellular uricase $\mathrm{Tg}$ animals was injected i.p. without exogenous uricase, we observed a similar reduction in inflammation relative to responses to WT lung (Figure 6, E and F). Therefore, uric acid depletion reduces inflammation to several types of dead cells and also in different anatomic locations (liver and peritoneum), although there are some quantitative differences in the degree of inhibition in these different situations.

Effect of uric acid depletion on inflammation due to sterile particulate or microbial stimuli. It was important to assess whether depleting uric acid was selectively affecting cell death-induced inflammation or whether it was generally immunosuppressive. To address this issue, we investigated to determine whether uric acid depletion would affect an inflammatory response in which uric acid should play no direct role. For this purpose, we injected sterile silica crystals, zymosan (yeast cell wall), or LPS i.p. into the various mouse models and quantified the ensuing inflammatory response. In untreated or buffer-treated WT animals, silica crystal, zymosan, and LPS elicit a neutrophilic inflammatory response similar to that of dead cells (Figure 7, A-C). There was no reduction in these inflammatory responses in the secreted or intracellular uricase $\mathrm{Tg}$ mice compared with WT animals (Figure 7, A-C). In fact, in the intracellular uricase $\mathrm{Tg}$ mice, the inflammatory responses to silica crystal, zymosan, and LPS were actually significantly increased for reasons that aren't clear but are presumably somehow related to the hydrolysis of intracellular uric acid. In any case, this increased response to the sterile particulate or microbial stimuli makes the inhibition of responses to dead cells even more impressive. Zymosan-induced inflammation was also not decreased in mice treated with exogenous uricase or allopurinol compared with control animals (Figure 7, D and E). Collectively, these results are important because they indicate that uric acid depletion does not cause a generalized defect in generating an acute inflammatory response but instead is selectively affecting cell death-induced inflammation.

\section{Discussion}

The major finding in this report is that depletion of uric acid in vivo inhibits the inflammatory response to cell death. This inhibitory effect was seen in responses to necrotic liver, lung, and lymphoma cells and whether these responses were occurring in the tissues (liver) or the peritoneum. Therefore, uric acid is playing a role in inflammation to cell death for multiple different cell types and in different anatomical locations. Based on these findings, we predict that uric acid will play this role generally in multiple tissues.

Why does uric acid depletion inhibit inflammation? This is almost certainly due to the loss of uric acid rather than a pleiotropic effect of the method of its depletion because inhibition was seen regardless of whether uric acid levels were lowered by blocking its synthesis, lowering intracellular stores through enhanced catabolism, and/or eliminating it from the extracellular fluids, either acutely or chronically. In theory, uric acid could be influencing inflammatory responses in a few different ways. It is an antioxidant, so it is possible that eliminating it could affect inflammation through an alteration in redox potential (29). However, a generalized alteration in redox is unlikely to be a major mechanism of action because inflammation was inhibited whether extracellular uric acid levels were reduced (uricase treatment) or not (allopurinol treatment). Even more importantly, depletion of uric acid selectively inhibits inflammation to cell death rather than to other stimuli including microbial stimuli or irritant particles (silica). These latter findings are important because they argue that uric acid is not functioning as a general modulator of inflammation, as might occur if it were generally affecting redox potential. Instead, uric acid's most likely mechanism of action is as a proinflammatory DAMP that is released from dying cells. This would be consistent with the known proinflammatory properties of monosodium urate (MSU). It would also explain the selective inhibition of cell death-induced inflammation by uric acid depletion. Moreover, it would explain why eliminating it intracellularly from dying cells or extracellularly after cell death would inhibit inflammation.

The model for uric acid acting as a proinflammatory DAMP is similar to the one that we have previously proposed $(7,8)$. All cells contain intracellular pools of uric acid produced from the catabolism of purines, and these concentrations are quite high. Moreover, we found in the present study that after cell death there is a burst of uric acid production, as purines, presumably 
A

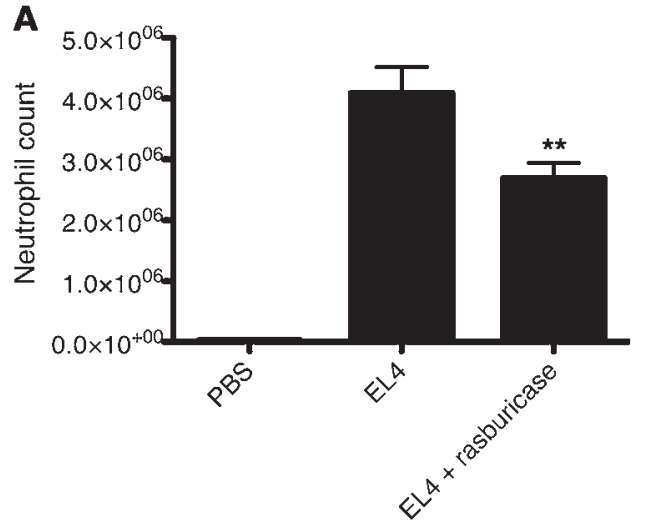

C

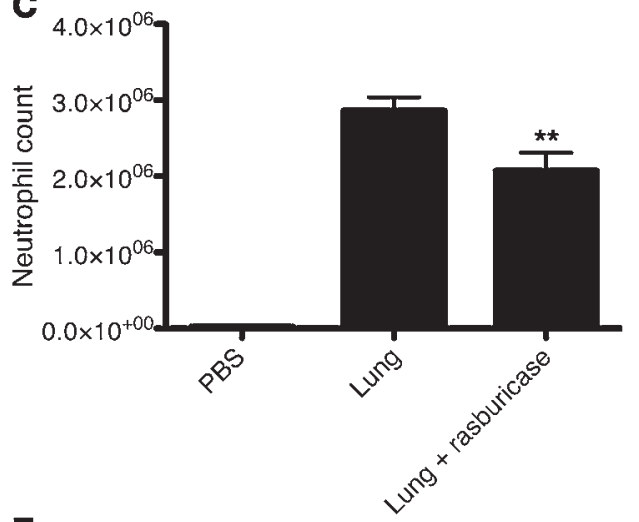

E

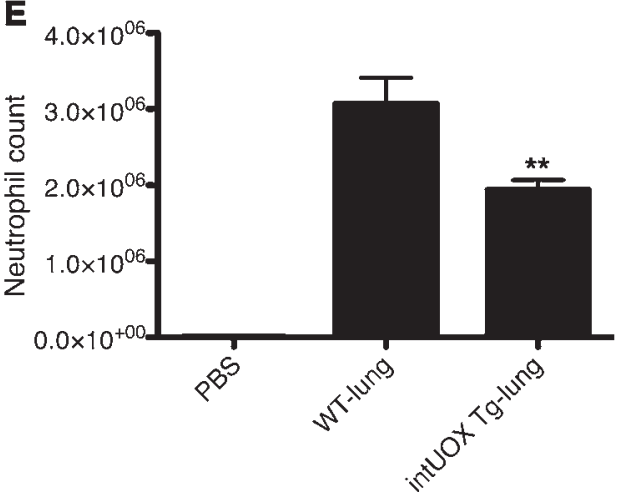

B

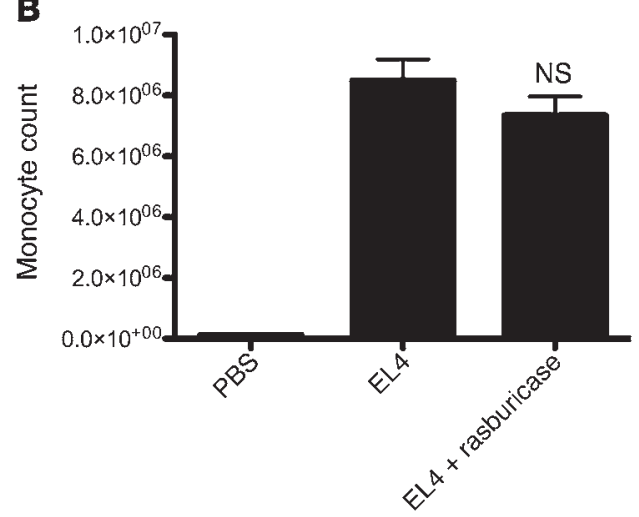

D

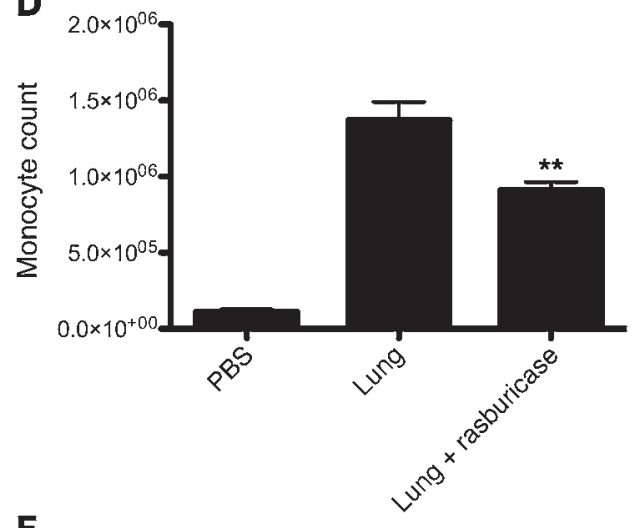

F

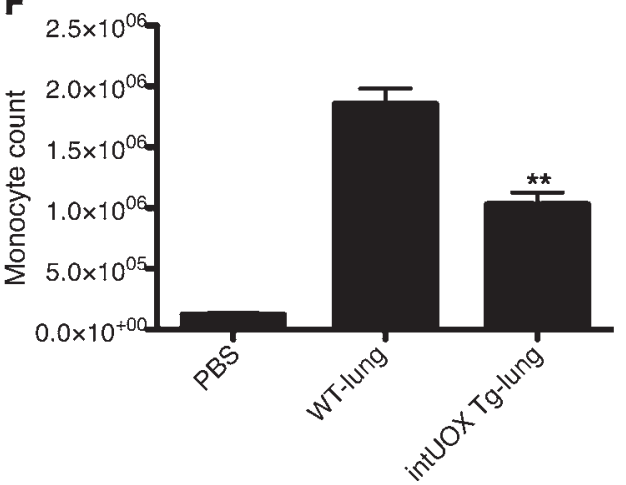

\section{Figure 6}

Reduced neutrophil recruitment in the peritoneal cavity in response to rasburicase-treated necrotic cells or lung from uricase Tg mice. Total neutrophil or monocyte numbers in the peritoneal cavity 15 hours after i.p. challenge with necrotic EL4 cells (A and $\mathbf{B})$ or lung homogenate from WT C57BL/6 (C and D) with or without $18 \mu \mathrm{g}$ of rasburicase. (E and F) Lung homogenate from WT or intracellular uricase Tg mice was injected i.p. into WT C57BL/6. Neutrophil or monocyte numbers in PEC were determined by counting the Ly- $6 \mathrm{G}^{+} 7 / 4^{+}$or Ly- $6 \mathrm{G}^{-} 7 / 4^{+} \mathrm{Cells}$ in $100 \mathrm{ul}$ of peritoneal lavage, respectively. Negative control: C57BL/6 mice challenged with PBS. Uric acid concentrations of EL4 cell suspension and WT lung homogenate injected were $5.4 \mathrm{mg} / \mathrm{dl}$ and $7.5 \mathrm{mg} / \mathrm{dl}$, respectively. Means and SEM values are for combined data from 3 or more independent experiments. Number of mice used in (A and B): $n=8$ (PBS); $n=15$ (EL4); $n=16$ (EL4 + rasburicase); (C and D): $n=10$ (PBS); $n=24$ (lung); $n=23$ (lung + rasburicase); (E and F): $n=4$ (PBS); $n=10$ (WT-lung); $n=10$ (intUOX Tg-lung). ${ }^{* *} P<0.01$; NS, not significant versus control necrotic EL4 without rasburicase (A and $\mathbf{B})$, lung homogenate without rasburicase (C and $\mathbf{D})$, or WT-lung (E and $\mathbf{F})$.

released by the action of nucleases on DNA and RNA, are converted by xanthine oxidase into uric acid. When this material is released into the extracellular fluids, the concentration of uric acid will exceed the saturation point in body fluids. Moreover, in the presence of the high levels of sodium in the extracellular fluids, the conditions should promote the nucleation of monosodium urate and, the hypothesis is, this is the biologically active form of the proinflammatory DAMP. While this model fits our data, it remains possible that uric acid is playing a role in some other way, e.g., by somehow controlling the release and/or activity of other DAMPs.

We had previously found that MSU and dead cells both stimulate sterile inflammation through the same final pathway $(19,30)$. Both induce IL-1, and this mediator is essential for the neutrophilic inflammation in these responses. In contrast, IL-1 is not necessary for inflammation stimulated by microbial products 

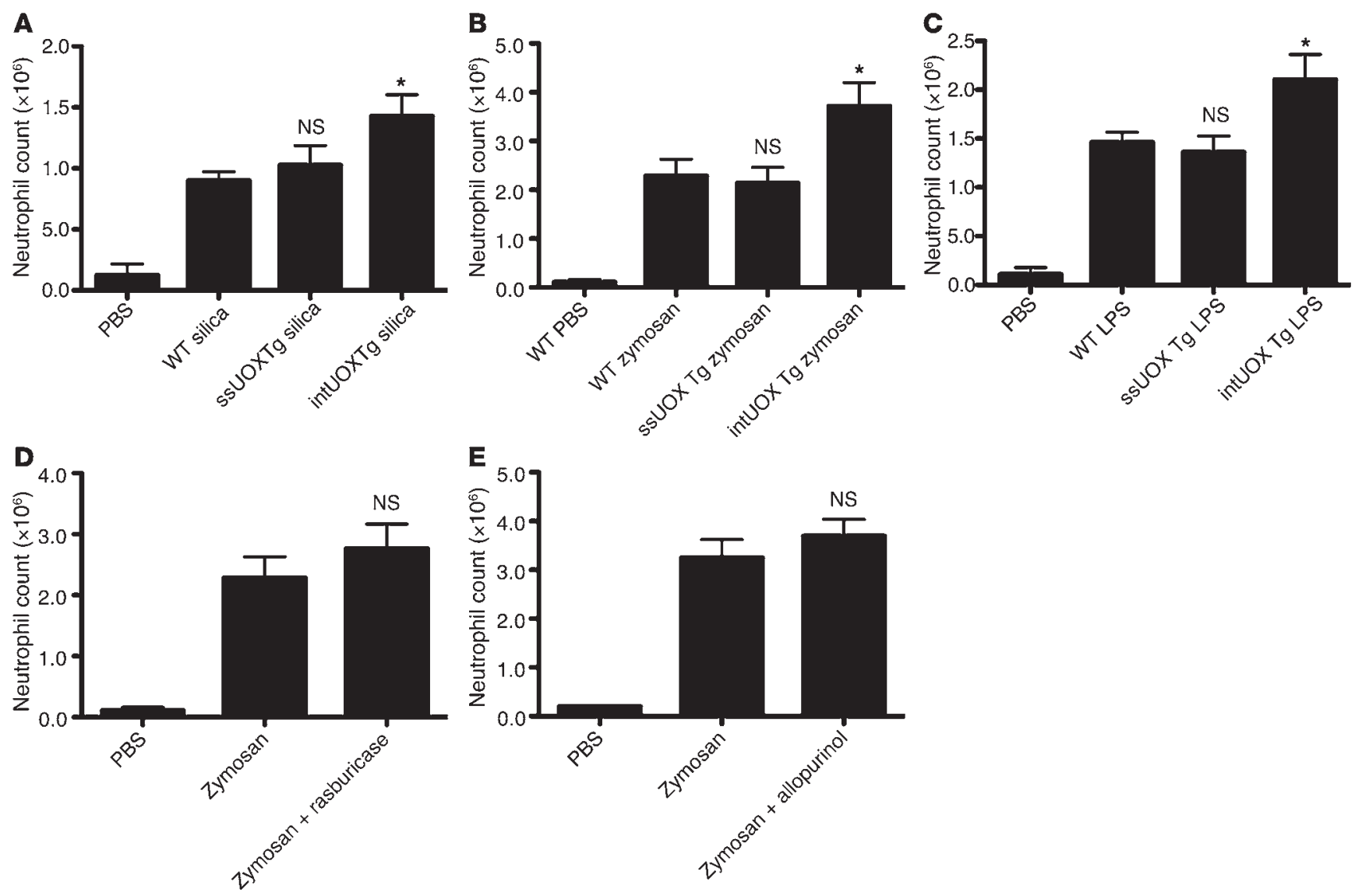

\section{Figure 7}

No decrease in neutrophil recruitment to silica crystals, zymosan, or LPS in uricase Tg mice or mice treated with rasburicase or allopurinol. Total number of neutrophils in the peritoneal cavity 15 hours after i.p. injection into WT or uricase Tg mice of $0.5 \mathrm{mg}$ of silica crystal (A), $0.2 \mathrm{mg}$ zymosan in uricase Tg mice (B), $100 \mathrm{ng}$ of ultrapure LPS (C), or rasburicase-treated mice (D), or injection of zymosan into control, or allopurinol-treated mice (E). Means and SEM values are for combined data from 3 or more independent experiments. Number of mice used in (A): $n=5$ (PBS), $n=11$ (WT silica), $n=8$ (ssUOX Tg silica); 6 (intUOX Tg silica); (B): $n=4$ (PBS); $n=15$ (WT zymosan); $n=15$ (ssUOX Tg zymosan); $n=17$ (intUOX Tg zymosan); (C): $n=9$ (PBS); $n=9$ (WT LPS); $n=9$ (ssUOX Tg LPS); $n=9$ (intUOX Tg LPS); (D): $n=4$ (PBS); $n=15$ (zymosan); $n=14$ (zymosan + rasburicase); (E) $n=4$ (PBS); $n=9$ (zymosan); $n=9$ (zymosan + allopurinol). ${ }^{*} P<0.05$; NS, not significant versus WT silica (A), WT zymosan (B), or WT LPS (C).

$(19,30)$. The present findings that dead cells work through uric acid may in part explain the common pathway.

Uric acid depletion inhibits cell death-induced inflammation only partially. Because uric acid is not completely eliminated in our studies, it is possible that its contribution to this response is being underestimated. To evaluate this point, it would be of interest to examine the effect of further reducing uric acid. We had hoped to achieve this with the uricase Tg mice, but despite analyzing multiple independent founders, we did not succeed in obtaining animals with more complete elimination. This raises the possibility that very low levels of uric acid levels are not permissive on a sustained basis. Despite being a "waste product," there are several mechanisms that maintain high levels in vivo, including absorption from the diet and reabsorption through the kidney; thus, uric acid might subserve some other useful function. In fact, we did find that while the secreted uricase Tg mice were healthy from birth through middle age, their survival past approximately 8 months was reduced; the basis for this increased mortality will be studied and reported on in the future.
Given the large number of potential DAMPs, it is perhaps surprising that the elimination of a single one like uric acid had any effect at all. This could indicate that there are relatively few proinflammatory DAMPs and/or that uric acid is one of the major ones. It is also possible that uric acid plays a role that is different from other proinflammatory DAMPs; uric acid is a small organic heterocyclic compound, while the other known DAMP candidates are proteins and therefore may work in different ways. If so, uric acid might provide additive or synergistic effects with other DAMPs. It would also not be surprising if different tissues have different contents of DAMPs, in which case a specific DAMP such as uric acid might play a greater or lesser role in different tissues. This might be one of the reasons in our experiments that uric acid depletion inhibits inflammation to different cell types to different degrees. It will be of interest to explore these possibilities in future studies.

The identification of proinflammatory DAMPs, such as uric acid, that play a role in vivo is of interest because these molecules are potential therapeutic targets. The inflammation stimulated by cell death is known to complicate acute ischemic and/or toxic 
injury to a number of organs, including the heart, liver, and lung, and is thought to also contribute to the pathogenesis of chronic diseases associated with cell death $(5,31,32)$. Therefore, it could potentially be of therapeutic benefit to block this sterile inflammatory response. To this end, inhibiting the action of proinflammatory DAMPs would be attractive because it should selectively inhibit inflammation to cell death without affecting the ability of the host to mount inflammatory responses in other settings such as infection. Based on the present results, it will be of interest to test this concept with uric acid, especially because there are already uric acid-lowering drugs available that are well tolerated and approved for use in humans.

\section{Methods}

Chemicals and biologicals. Uric acid, allopurinol, acetaminophen, and zymosan were purchased from Sigma-Aldrich. UltraPure LPS was obtained from Invivogen (LPS-SM). Rasburicase (EC 1.7.3.3, recombinant uricase from Aspergillusflavus) was obtained from sanofi-aventis. Goat anti-uricase polyclonal antibody was from Santa Cruz Biotechnology Inc. Monoclonal anti- $\alpha$-tubulin was from Abcam. Ly6G-FITC, anti-CD3e (145-2C11), and streptavidin-APC were from BD Bioscience. Biotinylated anti-7/4 was from AbD Serotec. Anti-CD45R (B220, clone RA3-6B2) and F4/80 (clone BM8) were from eBioscience.

Animals and cell lines. C57BL/6 and B6129 mice were purchased from Jackson Laboratory. To produce uricase $\mathrm{Tg}$ mice, a full-length cDNA for uricase was cloned from murine liver by RT-PCR. A secreted form of this enzyme was constructed by addition of signal sequence from adenovirus gp19K to the N terminus of the uricase cDNA. Secreted or unmodified (intracellular) uricase cDNAs were subcloned into pCAGGS (26) and injected into fertilized eggs from C57BL/6 mice that were then implanted into female mice to produce $\mathrm{Tg}$ mice. Primers used for genotyping were 5'-CAGCCATTGCCTTTTATGGT-3' and 5'-CAGGACGTGCACAGTGTTCT- $3^{\prime}$. The presence of the uricase transgene was further verified by Western blot of tissue lysates and measuring uricase activity in blood samples. All animal protocols were approved by the University of Massachusetts Medical School Animal Care and Use Committee. EL4 cells were maintained in RPMI with 10\% FCS and antibiotics (Invitrogen) and tested negative for mycoplasma contamination (Lonza).

Uricase activity assay. To measure uricase activity in tissues, organs were harvested from mice and mixed with 4 times their weight in lysis buffer $(20 \mathrm{mM}$ Tris-HCl, pH 7.4, $150 \mathrm{mM} \mathrm{NaCl}, 1 \mathrm{mM}$ EDTA, $1 \%$ Triton $\mathrm{X}-100$, and $0.1 \%$ SDS, complete protease inhibitor; Roche Diagnostics $\mathrm{GmbH}$ ) and homogenized with a tissue tearer followed by ultrasound sonication. After centrifugation at $15,000 \mathrm{~g}$ for 10 minutes, clarified supernatant was collected and assayed for protein concentration by the bicinchoninic acid method (Thermo Scientific). Lysate (20 $\mu \mathrm{l})$ was added to $1 \mathrm{ml}$ of uric acid solution ( 1.0 of $\mathrm{OD}_{292}$ in $0.1 \mathrm{M}$ boric acid, $\mathrm{pH} 8.5$ ) and incubated at $37^{\circ} \mathrm{C}$. Reduction of $\mathrm{OD}_{292}$ of the uric acid solution was measured by spectrophotometer.

Western blot. Cleared lysates prepared as described above were measured for protein concentration, and a total of $10 \mu \mathrm{g}$ of protein was fractionated by SDS-PAGE on a $10 \%$ gel, transferred to nitrocellulose membrane, and blotted with antibodies against uricase or $\alpha$-tubulin.

Uric acid measurement. To measure uric acid in peritoneal cavity, the peritoneal cavity of mice was lavaged with $6 \mathrm{ml}$ of physiological saline. Four $\mathrm{ml}$ of peritoneal lavage fluid was lyophilized and resuspended in $150 \mu \mathrm{l}$ of water. The reconstituent was passed through an ultrafiltration membrane ( $3 \mathrm{~K}$ cutoff; Pall Life Sciences), and the filtrate was assayed for uric acid content (Bioassay Systems). The concentration of uric acid was also verified by HPLC using Superdex 200 (GE Healthcare). To measure uric acid concentration in tissues, the tissue lysates prepared as described above were kept cold or incubated at $37^{\circ} \mathrm{C}$ for the indicated time, passed through an ultrafiltration membrane, and assayed for uric acid concentration; the concentrations reported in the figures are those in the lysates, which are much lower than those actually in cells (13) due to dilution in buffer.

Cell injury induction. EL4 cells were washed 5 times with PBS and resuspended in PBS at 10 million cells $/ 50 \mu$ l. Cells were heat-shocked at $45^{\circ} \mathrm{C}$ for 10 minutes and incubated at $37^{\circ} \mathrm{C}$ for 5 hours. Mouse lung was washed 5 times with PBS; the harvested lung was weighed and 5 times its weight in PBS was added, and then it was homogenated with a metal blade tissue tearer followed by 5 freeze-thaw cycles and $37^{\circ} \mathrm{C}$ incubation for 5 hours. Nine $\mu \mathrm{g}$ of rasburicase was added to $150 \mu$ l of cell suspension or lung homogenate at the start and end of a 5-hour incubation period.

Acetaminophen treatment and MPO assay. Mice were fasted for 18 hours and were then injected i.p. with $300 \mathrm{mg} / \mathrm{kg}$ acetaminophen (APAP) or $20 \mathrm{ml} / \mathrm{kg}$ PBS. Eighteen hours after APAP administration, blood was drawn for serum collection and ALT assay (Synchron LX Systems; Beckman Coulter), and mice were euthanized to obtain liver tissues for MPO activity assay; MPO is a neutrophil enzyme and a marker that is well validated for quantifying neutrophil infiltration into tissues (33). There were no difference in the MPO activities in the neutrophil in UOX Tg mice (Supplemental Figure 6B). In some experiments, mice were treated either with $18 \mu \mathrm{g}$ of rasburicase i.p. at the same time as APAP treatment or with 1 week of allopurinol (10 mg/kg/d) i.p. injection daily before APAP treatment. After perfusion with PBS, $100 \mathrm{mg}$ of liver was homogenized in $1 \mathrm{ml}$ of MPO buffer (50 $\mathrm{mM} \mathrm{Na}_{2} \mathrm{HPO}_{4}$, pH 5.4, 0.5\% hexadecyl trimethyl ammonium bromide, $10 \mathrm{mM}$ EDTA) using a tissue tearer and sonication. After centrifuge at $2500 \mathrm{~g}, 15$ minutes at $4{ }^{\circ} \mathrm{C}, 25 \mu \mathrm{l}$ of supernatant was added with $25 \mu \mathrm{l}$ of assay buffer $(16.7 \mathrm{mg} / \mathrm{ml}$ of o-Dianisidine in $50 \mathrm{mM}$ $\mathrm{Na}_{2} \mathrm{HPO}_{4}, \mathrm{pH} 5.4$ ) and $200 \mu \mathrm{l}$ of development solution (30 $\mu \mathrm{l}$ of $31.1 \%$ $\mathrm{H}_{2} \mathrm{O}_{2}$ per $10 \mathrm{ml}$ of $50 \mathrm{mM} \mathrm{Na}_{2} \mathrm{HPO}_{4}, \mathrm{pH}$ 5.4). The $\mathrm{OD}_{450}$ change was measured using Bio-Rad 3550 microplate reader, and the rate between time 0 and 2 minutes 20 seconds was calculated.

Preparation of hepatic leukocytes and analysis by flow cytometry. After 18 hours of administration of APAP, livers were perfused with HBSS and liver digestion buffer (HBSS, $1.25 \mathrm{mM} \mathrm{CaCl}_{2}, 4 \mathrm{mM} \mathrm{MgCl}_{2}, 0.05 \%$ collagenase type IV, $0.028 \%$ DNAseI). Livers were homogenized and incubated in the digestion buffer for an hour at $37^{\circ} \mathrm{C}$ and passed through a $70-\mu \mathrm{m}$ filter. Nonparenchymal cells were collected from the supernatant of centrifugation at $30 \mathrm{~g}$ and further purified from the interface in $22 \%$ of Opti Prep and RPMI 1640. The cells were stained with Ly6G and 7/4 antibodies to detect neutrophils and monocytes, anti-F4/80 antibody for macrophages, anti-CD3 antibody for T cells, and B220 antibody for B cells. The absolute number of cells was quantified using a flow cytometer with high-throughput sampler (BD Bioscience). Data were acquired by CellQuest software (BD Biosciences) and analyzed by FlowJo software (Tree Star Inc.).

Measurement of neutrophil recruitment to peritoneal cavity. To analyze the neutrophil recruitment to necrotic cells, mice were administered i.p. with 30 million cells of necrotic EL4 cells or $150 \mu \mathrm{l}$ of lung homogenate. $0.2 \mathrm{mg}$ of zymosan or $100 \mathrm{ng}$ of pure LPS was also used to induce peritonitis. Fifteen hours after injection, animals were euthanized by $\mathrm{CO}_{2}$ exposure, and their peritoneal cavities were washed with $6 \mathrm{ml}$ of RPMI with $10 \%$ FCS containing $3 \mathrm{mM}$ EDTA and $10 \mathrm{U} / \mathrm{ml}$ heparin. The cells were stained with $\mathrm{mAbs}$ Ly-6G-FITC and 7/4-biotin for 30 minutes at $4^{\circ} \mathrm{C}$ in the presence of $\mathrm{mAb} 2.4 \mathrm{G} 2$ (FcyRIIB/III receptor blocker). The cells were further incubated with streptavidin-APC. Following staining, cells were washed with PBS with $2 \%$ FCS and resuspended with the original volume of the starting material. The total number of neutrophils or monocytes in the peritoneal exudate cells (PECs) was determined by the count of $\mathrm{Ly}-6 \mathrm{G}^{+} 7 / 4^{+}$or $\mathrm{Ly}-6 \mathrm{G}^{-} 7 / 4^{+}$cells in $100 \mu \mathrm{l}$ of stained cells with a flow cytometer, respectively (FACSCalibur 
with high-throughput sampler). The results of the quantification of neutrophils in this assay correlates well with MPO levels in lysates of the lavage fluid (Supplemental Figure 6A).

Histology. 5- $\mu \mathrm{m}$ thickness sections from formalin-fixed and paraffinembedded liver were cut on a microtome. To detect neutrophils, sections were stained with naphthol AS-D chloroacetate esterase according to manufacturer's instructions (Sigma-Aldrich). Neutrophil number was counted in 10 high-power fields $(\times 400)$ in each mouse using a Nikon Eclipse E800 Microscope. Ten low-power field $(\times 100)$ pictures of each mouse were obtained from $\mathrm{H} \& \mathrm{E}$-stained sections and the necrotic area quantified with Image $1.42 \mathrm{q}(\mathrm{NIH})$ software.

Statistics. Statistical analysis in each independent experiment was performed with an unpaired, 2-tailed Student's $t$ test. Data are reported as mean \pm SEM. One-way ANOVA and Dunnett's multiple comparison post test were used to compare the means of multiple groups to the control group. $P<0.05$ was considered statistically significant.

\section{Acknowledgments}

We thank Karen Dresser, Sharlene Hubbard, Matthew Janko, Zubin Patel, and Dipti Karmarkar for technical assistance. This work was supported by grants to K.L. Rock from the NIH and the American Asthma Foundation. Funding for this study was partially provided by sanofi-aventis US to $\mathrm{H}$. Kono. Core resources supported by the Diabetes Endocrinology Research Center grant DK32520 were also used.

Received for publication June 8, 2009, and accepted in revised form March 3, 2010.

Address correspondence to: Kenneth L. Rock, Department of Pathology, University of Massachusetts Medical School, 55 Lake Ave. North, Worcester, Massachusetts 01655, USA. Phone: 508.856.2521; Fax: 508.856.1094; E-mail: Kenneth.rock@umassmed.edu.
1. Majno G, La Gattuta M, Thompson TE. Cellular death and necrosis: chemical, physical and morphologic changes in rat liver. Virchows Arch Pathol Anat Physiol Klin Med. 1960;333:421-465.

2. Acute myocardial infarction. In: Braunwald E, Zipes DP, and Libby P, eds. Heart Disease: A Textbook of Cardiovascular Medicine. 6th ed. Philadelphia, PA: WB Saunders; 2001:1114-1231.

3. Majno G, Joris I. Apoptosis, oncosis, and necrosis. An overview of cell death. Am J Pathol. 1995;146(1):3-15.

4. Romson JL, Hook BG, Kunkel SL, Abrams GD, Schork MA, Lucchesi BR. Reduction of the extent of ischemic myocardial injury by neutrophil depletion in the dog. Circulation. 1983;67(5):1016-1023.

5. Sawa Y, et al. Leukocyte depletion attenuates reperfusion injury in patients with left ventricular hypertrophy. Circulation. 1996;93(9):1640-1646.

6. Jaeschke H, Hasegawa T. Role of neutrophils in acute inflammatory liver injury. Liver Int. 2006;26(8):912-919.

7. Kono H, Rock KL. How dying cells alert the immune system to danger. Nat Rev Immunol. 2008;8(4):279-289.

8. Rock KL, Kono H. The inflammatory response to cell death. Annu Rev Pathol. 2008;3:99-126.

9. Matzinger P. Tolerance, danger, and the extended family. Annu Rev Immunol. 1994;12:991-1045.

10. Lotze MT, et al. The grateful dead: damage-associated molecular pattern molecules and reduction/oxidation regulate immunity. Immunol Rev. 2007;220:60-81.

11. Bianchi ME. DAMPs, PAMPs and alarmins: all we need to know about danger. J Lenkoc Biol. 2007;81(1):1-5.

12. Scaffidi P, Misteli T, Bianchi ME. Release of chromatin protein HMGB1 by necrotic cells triggers inflammation. Nature. 2002;418(6894):191-195.

13. Shi Y, Evans JE, Rock KL. Molecular identification of a danger signal that alerts the immune system to dying cells. Nature. 2003;425(6957):516-521.
14. Maeda S, Kamata H, Luo JL, Leffert H, Karin M. IKKbeta couples hepatocyte death to cytokinedriven compensatory proliferation that promotes chemical hepatocarcinogenesis. Cell. 2005;121(7):977-990.

15. Yamasaki S, Ishikawa E, Sakuma M, Hara H, Ogata $\mathrm{K}$, Saito T. Mincle is an ITAM-coupled activating receptor that senses damaged cells. Nat Immunol. 2008;9(10):1179-1188.

16. Zhang $M$, et al. Identification of the target self-antigens in reperfusion injury. J Exp Med. 2006;203(1):141-152

17. Weathington NM, et al. A novel peptide CXCR ligand derived from extracellular matrix degradation during airway inflammation. Nat Med. 2006;12(3):317-323.

18. Jiang D, et al. Regulation of lung injury and repair by Toll-like receptors and hyaluronan. Nat Med. 2005;11(11):1173-1179.

19. Chen CJ, Kono H, Golenbock D, Reed G, Akira S, Rock KL. Identification of a key pathway required for the sterile inflammatory response triggered by dying cells. Nat Med. 2007;13(7):851-856.

20. Shi Y, Galusha SA, Rock KL. Cutting edge: elimination of an endogenous adjuvant reduces the activation of CD8 T lymphocytes to transplanted cells and in an autoimmune diabetes model. J Immunol. 2006;176(7):3905-3908.

21. McCarty DJ, Hollander JL. Identification of urate crystals in gouty synovial fluid. Ann Int Med. 1961;54:452-460.

22. Pacher P, Nivorozhkin A, Szabo C. Therapeutic effects of xanthine oxidase inhibitors: renaissance half a century after the discovery of allopurinol. Pharmacol Rev. 2006;58(1):87-114.

23. Cammalleri L, Malaguarnera M. Rasburicase represents a new tool for hyperuricemia in tumor lysis syndrome and in gout. Int J Med Sci. 2007;4(2):83-93.

24. Ohtsubo T, Rovira II, Starost MF, Liu C, Finkel T. Xanthine oxidoreductase is an endog- enous regulator of cyclooxygenase-2. Circ Res. 2004;95(11):1118-1124.

25. Wilson-Rawls J, Deutscher SL, Wold WS. The signal-anchor domain of adenovirus E3-6.7K, a type III integral membrane protein, can direct adenovirus E3-gp19K, a type I integral membrane protein, into the membrane of the endoplasmic reticulum. Virology. 1994;201(1):66-76.

26. Miyazaki J, et al. Expression vector system based on the chicken beta-actin promoter directs efficient production of interleukin-5. Gene. 1989;79(2):269-277.

27. Enomoto A, et al. Molecular identification of a renal urate anion exchanger that regulates blood urate levels. Nature. 2002;417(6887):447-452.

28. Liu ZX, Han D, Gunawan B, Kaplowitz N. Neutrophil depletion protects against murine acetaminophen hepatotoxicity. Hepatology. 2006;43(6):1220-1230.

29. Ames BN, Cathcart R, Schwiers E, Hochstein $P$. Uric acid provides an antioxidant defense in humans against oxidant- and radical-caused aging and cancer: a hypothesis. Proc Natl Acad Sci US A. 1981;78(11):6858-6862.

30. Chen CJ, et al. MyD88-dependent IL-1 receptor signaling is essential for gouty inflammation stimulated by monosodium urate crystals. J Clin Invest. 2006;116(8):2262-2271.

31. Sekido N, Mukaida N, Harada A, Nakanishi I, Watanabe Y, Matsushima K. Prevention of lung reperfusion injury in rabbits by a monoclonal antibody against interleukin-8. Nature. 1993;365(6447):654-657.

32. Jaeschke H. Mechanisms of Liver Injury. II. Mechanisms of neutrophil-induced liver cell injury during hepatic ischemia-reperfusion and other acute inflammatory conditions. Am J Physiol Gastrointest Liver Physiol. 2006;290(6):G1083-G1088.

33. Mullane KM, Kraemer R, Smith B. Myeloperoxidase activity as a quantitative assessment of neutrophil infiltration into ischemic myocardium. J Pharmacol Methods. 1985;14(3):157-167. 